\title{
BMJ Open Cohort study of healthcare use, costs and diagnoses from onset to 6 months after discharge for takotsubo syndrome in Sweden
}

\author{
Sara Wallström, ${ }^{\oplus 1,2}$ Inger Ekman, ${ }^{1,2}$ Elmir Omerovic, ${ }^{3,4}$ Kerstin Ulin, ${ }^{1,2}$ \\ Hanna Gyllensten ${ }^{1,2}$
}

To cite: Wallström S, Ekman I, Omerovic E, et al. Cohort study of healthcare use, costs and diagnoses from onset to 6 months after discharge for takotsubo syndrome in Sweden. BMJ Open 2019;9:e027814. doi:10.1136/ bmjopen-2018-027814

- Prepublication history for this paper is available online. To view these files, please visit the journal online (http://dx.doi org/10.1136/bmjopen-2018027814).

Received 8 November 2018 Revised 17 January 2019 Accepted 29 January 2019

Check for updates

(C) Author(s) (or their employer(s)) 2019. Re-use permitted under CC BY-NC. No commercial re-use. See rights and permissions. Published by BMJ.

${ }^{1}$ Institute of Health and Care Sciences, Sahlgrenska Academy, University of Gothenburg, Gothenburg, Sweden

${ }^{2}$ University of Gothenburg Centre for Person-Centred Care, Sahlgrenska Academy, University of Gothenburg, Gothenburg, Sweden ${ }^{3}$ Department of Cardiology, Sahlgrenska University Hospital, Gothenburg, Sweden ${ }^{4}$ Department of Molecular and Clinical Medicine, Sahlgrenska Academy, University of Gothenburg, Gothenburg, Sweden

Correspondence to Dr Sara Wallström; sara.wallstrom@gu.se

\section{ABSTRACT}

Objective Little is known about the economic impact of takotsubo syndrome (TS) for patients and the health system after initial discharge from hospital. Therefore, the aim of this study was to describe the healthcare resource use and calculate direct healthcare costs for TS, from hospitalisation to 6 months after discharge, and explore the distribution of costs between TS and other diagnoses among patients with TS.

Method, participants and setting Cohort study investigating direct healthcare costs from hospitalisation, open specialised outpatient and primary care. Healthcare resource use during 6 months after diagnosis with TS was collected for 58 consecutive patients from the Regional Patient Register. Incidence-based direct healthcare costs, in 2015 values, were calculated using diagnosis-related group weights and unit costs from national statistics on healthcare costs.

Results The mean length of hospital stay was 10.2 days, index 6.4 and re-admissions 3.8 days. The mean number of follow-up encounters per patient was 15.6, of which two-thirds was specialised outpatient and onethird was primary care. This resulted in an average cost of $€ 10360$. Of this, costs of $€ 8026$ (77.5\%) occurred during encounters for which at least one of the registered conditions was cardiovascular. Costs differed little according to background characteristics.

Conclusion This study shows that patients utilise hospital, specialised outpatient and primary care after discharge for TS. Most direct healthcare costs relate to cardiac diagnoses. Patients with TS would probably benefit from a supportive follow-up programme after discharge from hospital.

\section{INTRODUCTION}

Takotsubo syndrome (TS) is a form of acute reversible heart failure, which usually recovers spontaneously in 12 weeks. Its clinical presentation at onset has similar features to those of an acute myocardial infarction (AMI) with chest pain, dyspnoea, ECG changes and raised markers of myocardial necrosis. ${ }^{12}$ TS is characterised by regional wall motion abnormalities affecting one or both ventricles of

\section{Strengths and limitations of this study}

This study explores an under-investigated area: cost of illness and health economics in patients with takotsubo syndrome (TS)

- Register offered the opportunity to investigate direct healthcare costs from inpatient, specialised outpatient and primary care.

- This study provides insight on the distribution of cost among patients with TS.

- Limitations include a small sample size, the limited study period and thatdata was limited to direct healthcare costs, which are based on proxy.

the heart and absence of a flow-limiting lesion in coronary arteries. The pathophysiological mechanisms underlying TS are not fully understood, but a surge of the hormone catecholamines is believed to play a vital part. Onset is often preceded by a stressful event, either psychological or physical. ${ }^{2}$

TS is most common among postmenopausal women; $84 \%-91 \%$ of cases are female and the mean age varies between 63 and 76 years. ${ }^{3-5}$ Knowledge regarding potential risk factors is scarce, but smoking, hyperlipidemia, alcohol abuse and anxiety have been recorded. ${ }^{6}$ Due to a lack of diagnosis uniformity, it has been difficult to determine the exact number of TS cases per annum, but estimates suggest that there are 50-100000 cases per year in the USA and a similar number in Europe. ${ }^{2}$ There are no reliable figures for Sweden, but an estimation based on population would be 1500-3000 cases per annum in Sweden. This is in line with the estimation of 2000 cases per annum in Sweden from the Swedish Coronary Angiography and Angioplasty Registry. ${ }^{7}$

TS was previously assumed to be relatively benign and to have little impact on long-term survival. However, recent studies have shown that TS affects both short-term and long-term 
survival, which are comparable to, or worse than, those in patients affected by AMI. ${ }^{48}$ Mortality from cardiovascular causes is comparable between these groups, but the excess mortality among patients with TS is related to non-cardiovascular or unknown causes. Male sex, Killip class III or IV at admission according to classification for heart failure and diabetes mellitus increases the likelihood of mortality among TS patients. ${ }^{8}$

There are currently a few guidelines for care or follow-up for patients with TS. At hospital investigations often include coronary angiography, ultra-cardiogram and cardiac biomarkers. Treatment is aimed at supportive care to sustain life and minimise complications during the recovery of normal cardiac function. At least one follow-up visit with a specialist after discharge from hospital to review medication and confirm recovery of cardiac function. ${ }^{2}$ Little is known of healthcare resources used for this follow-up. To the best of our knowledge, there are only two published studies examining costs after TS, both conducted in one American setting. These studies calculated the average cost of hospital stay for patients with TS to US $\$ 16723$ in $2007-2011^{9}$ and the total average charges to US\$61 034 in 2006-2010 for TS patients without arrhythmias ${ }^{10}$ (concurrent arrhythmias may increase the average inpatient charge by US $\$ 11334) .{ }^{10}$

To the best of our knowledge, there are no studies on the utilisation of healthcare resources for TS from Europe, which health system in many aspects is different from that in the USA. In addition, little is known about the economic impact of TS for patients and the health system after initial discharge from hospital. Such studies, often called cost of illness (COI) studies, are useful both for comparing the burden on the healthcare system, of TS to other diseases, and to identify important costs and variation in costs in the treatment of a specific disease, such as TS. ${ }^{11}$ Therefore, the aim of this study was to describe the healthcare resource use and calculate direct healthcare costs for TS, from hospitalisation to 6 months after discharge, and explore the distribution of costs between TS and other diagnoses among patients with TS.

\section{METHODS}

\section{Study population and settings}

Patients from two hospitals in a city in western Sweden were included consecutively from January 2012 to October 2015. There is no specific code in the Swedish version of International Statistical Classification of Diseases and Related Health Problems, 10th revision (ICD-10), so all coronary angiography records from the participating hospitals were screened to identify patients with TS. Patients were included after identification with coronary angiography and confirmation of diagnosis with a cardiologist. The inclusion criteria were (1) having a diagnosis of TS, (2) speaking Swedish, (3) having a predicted survival of more than 6 months and (4) living in Region Västra Götaland. In total, 110 patients with TS were identified during the study period: of those, 29 declined participation, 10 had a predicted survival of less than 6 months, five did not speak Swedish or were otherwise unable to fill out the questionnaires, two participated in another incompatible research study, two died and four accepted participation but were excluded because they did not live in Region Västra Götaland and thus, not possible to follow through register data. The remaining 58 patients with TS were included in the study.

\section{Data collection}

Clinical information about the disease and potential risk factors, for example, cardiovascular disease history, nicotine use, Killip class and hypertension, were retrieved from medical records during the initial hospital stay. Data on socioeconomic characteristics were collected from each participant using a questionnaire. Register data about use of healthcare resources and its cost were obtained from the Regional Patient Register (VEGA), which contains information about all inpatient care, specialised outpatient care, and primary care in the Region Västra Götaland. The VEGA-database has a nearly full coverage of care utilised by the residents of the region. ${ }^{12}{ }^{13}$ Costs for medications and healthcare provided by the municipalities were not included. Patient information retrieved covered the period from the day patients were admitted to hospital for TS and the following 6 months. Healthcare encounters were classified based on the main diagnosis registered, according to the ICD-10, as chapters A-Z and using a more detailed level for categorising disorders within chapter I (circulatory system disorders).

Incidence-based direct healthcare costs were calculated for consecutive patients, including costs for healthcare resource use during the 6 months starting at diagnosis with TS for each patient. Both all-cause costs and costs for resource use for which cardiovascular causes was the main diagnosis were calculated. Calculations were made based on the economic perspective of the healthcare sector and in 2015 values. Costs for specialised healthcare were calculated using diagnosis-related group (DRG) weights, retrieved from VEGA. ${ }^{14}$ Costs calculated from DRG weights were updated to 2015 values using the Swedish healthcare inflation index, which is a price index for the counties. ${ }^{15}$ Primary care encounters were assigned unit costs based on national statistics for healthcare use and costs. ${ }^{16}$ According to national statistics, the cost for primary care physician visits was SEK 1397 (€149) in primary care in 2014; this was updated to 2015 values using the Swedish healthcare inflation index. A visit to other healthcare personnel was weighted as $40 \%$ of the cost of a physician visit, phone calls were weighted as one-third of the cost of a visit and home healthcare as twice the cost of a visit. ${ }^{16}$ Length of stay in hospital is recorded for each hospital in the registry; thus, transfers between hospitals is registered as re-admissions. Indirect costs resulting from lost productivity and intangible costs for harm and suffering were not included in the analyses.

For two participants, information about the index hospitalisation was not obtained from VEGA. Data for 
these participants was requested a second time to eliminate errors in the database extraction but no data could be obtained. Instead, length of hospital stay and diagnosis were identified from the electronic medical records and the cost was calculated based on the median cost per day for the other participants' index hospitalisation multiplied by the number of days in hospital identified from the medical records. Using the median provides a conservative estimate of the cost. Register data for follow-up visits was obtained correctly for both the patients. Costs in EUR and USD were calculated using the average exchange rate of 2015 (€1=SEK 9.3562 and US $\$ 1=$ SEK 8.435). ${ }^{17}$

\section{Analyses}

Descriptive statistics were used to explore the clinical information and the background characteristics of the study population. Quantities and direct healthcare costs were calculated, by type of resource use and diagnoses. Due to the expected skewed distribution of costs, CIs for costs were calculated using bootstrap (using 1000 iterations, seed 1234).$^{18}$ For the baseline clinical data, SPSS V.22 (IBM Corp., Armonk, NY, USA) was used. For the register data, statistical analyses were performed using Stata SE V.14.2 (Stata Corp, College Station, TX, USA).

\section{Patient and public involvement}

Patients and/or public were not involved in this study.

\section{RESULTS}

Of the 58 patients included, $53(91.4 \%)$ were women and five $(8.6 \%)$ men (table 1$)$. In total, the 58 patients with TS were hospitalised for 593 days during the study period, which equals a mean of 10.2 days per person. The baseline hospitalizations length of stay was on average 6.4 days (IQR: 2-8). In addition, 20 of the 58 patients were re-admitted a total of 40 times during the 6-month study period (median two re-admissions per re-admitted patient, range 1-5). Eleven of these patients were re-admitted during the first 30 days. There were a total of 18 re-admissions during the first 30 days, and 10 of these had registered conditions belonging to in circulatory system diseases (chapter I) in ICD-10. The hospitalizations of eight people (13 re-admissions within 30 days) had a main diagnosis in the ICD sub-chapters I42-I429 (cardiomyopathy), where TS is usually registered. An additional three re-admissions were for circulatory system disorders (main diagnosis). During the 6 months, 19 re-admissions were for circulatory system disorders (main diagnosis), and 13 were for the ICD sub-chapters I42-I429 (cardiomyopathy). A further two were for unexplained chest pain (R074).

The 58 patients with TS had on average 15.6 follow-up encounters per patient during the 6 months following discharge for TS. This includes all categories of healthcare professionals, both direct and indirect (eg, telephone contact, writing letter, etc) encounters and visits with both specialist outpatient clinics and primary care.
Table 1 Sociodemographic and disease characteristics among 58 patients diagnosed with TS

\begin{tabular}{|c|c|}
\hline & $\begin{array}{l}\text { Patients with TS } \\
n=58\end{array}$ \\
\hline Women (\%) & $53(91.4)$ \\
\hline Age median (range) & $67.6(39-86)$ \\
\hline \multicolumn{2}{|l|}{ Marital status* } \\
\hline Married/co-habitant (\%) & $31(54.4)$ \\
\hline Single (\%) & $5(8.8)$ \\
\hline Divorced (\%) & $12(21.1)$ \\
\hline Widow/widower (\%) & $9(15.8)$ \\
\hline \multicolumn{2}{|l|}{ Education* } \\
\hline Primary and secondary (\%) & $33(57.9)$ \\
\hline High (\%) & $24(41.4)$ \\
\hline Country of birth, Sweden* (\%) & 49 (86.0) \\
\hline \multicolumn{2}{|l|}{ Nicotine use $\dagger$} \\
\hline Current (\%) & $11(21.2)$ \\
\hline Previous (\%) & 19 (34.6) \\
\hline \multicolumn{2}{|l|}{ Cardiovascular disease history } \\
\hline Previous AMI (\%)‡ & $6(11.1)$ \\
\hline Previous stroke (\%)§ & $3(5.4)$ \\
\hline Previous angina $(\%)^{*}$ & $2(3.6)$ \\
\hline Diabetes mellitus (\%)§ & $3(5.4)$ \\
\hline Hypertension (\%)* & $31(54.4)$ \\
\hline \multicolumn{2}{|l|}{ Killip class* } \\
\hline 1 & $40(70.2)$ \\
\hline II & $13(22.8)$ \\
\hline III & $4(7.0)$ \\
\hline IV & $0(0)$ \\
\hline
\end{tabular}

*One missing, †Six missing, ‡Four missing and §two missing. AMI, acutemyocardial infarction; TS, takotsubo syndrome.

The most common form of outpatient care utilised was physician visits, followed by physiotherapist or occupational therapist, which include cardiac rehabilitation groups, and registered nurse $(\mathrm{RN})$ visits. Other visits in outpatient care include consular, biomedical analyst, audiologist, assistant nurse and psychologist. In primary care, visits with physicians was also most common but here followed by $\mathrm{RN}$ visits. Other visits in primary care included consular, assistant nurse, podiatrist and psychologist.

When dividing costs by care level (table 2), the most costs were associated with the index hospitalisation (€260 623), followed by re-admissions (€169 739), outpatient care $(€ 143911)$ and primary care $(€ 26602)$. The average cost per index hospitalisation and re-admission were almost the same: $€ 4494$ and $€ 4243$, respectively. The total cost for outpatient and primary care for the 58 patients during the 6 months following discharge for TS was $€ 170514$. 


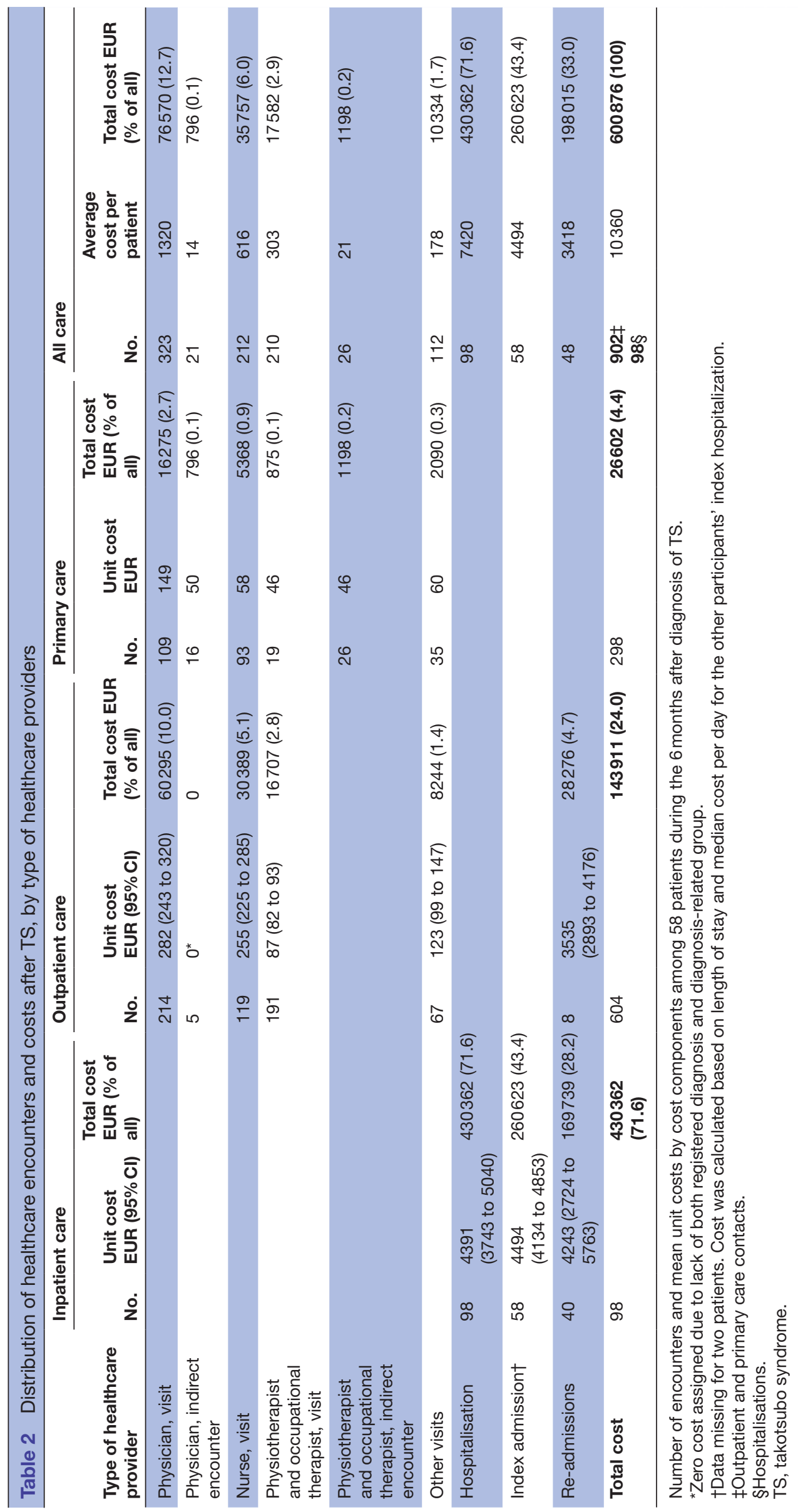

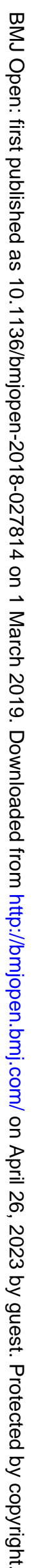


Table 3 Mean direct healthcare costs after TS, by person characteristics

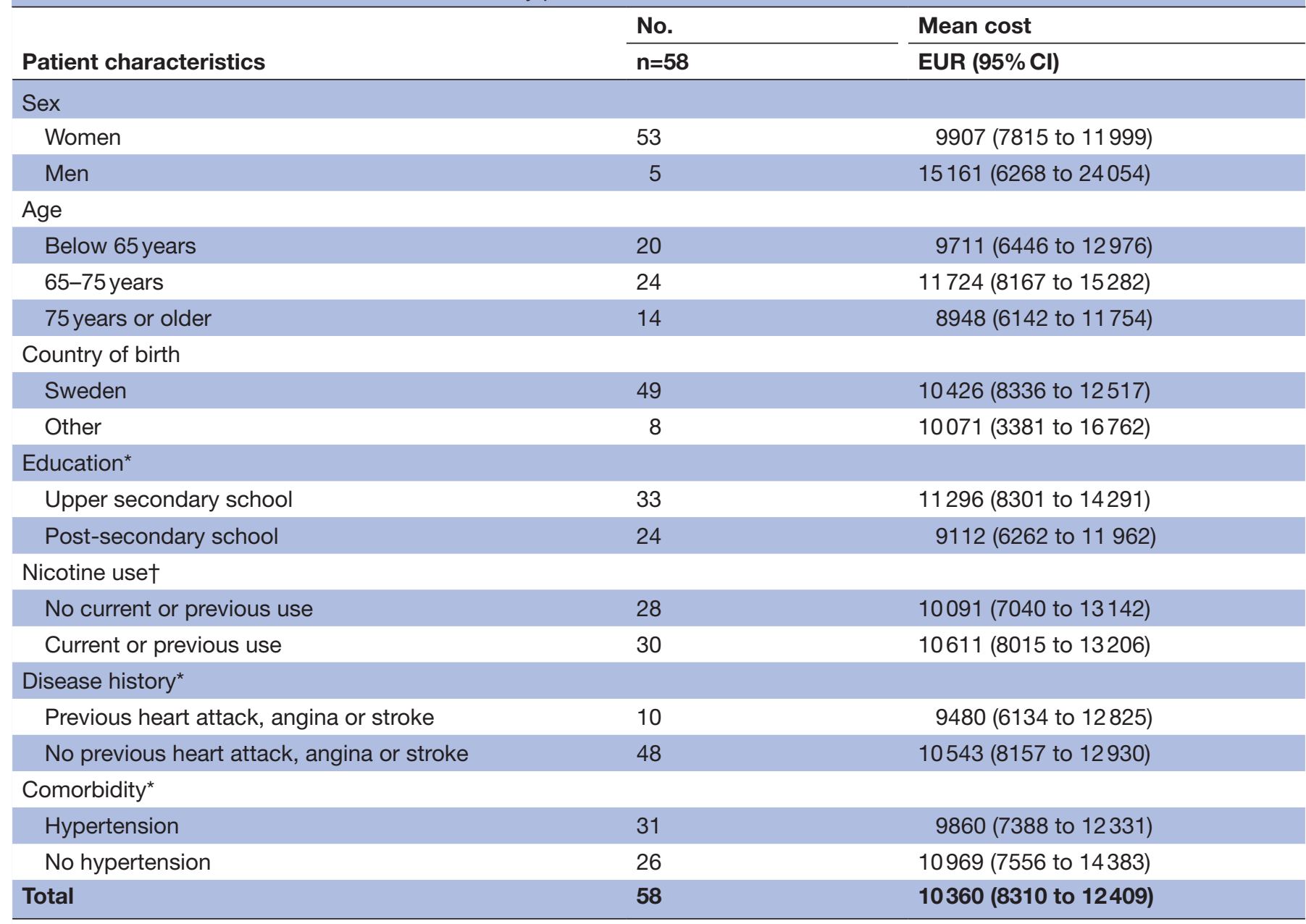

${ }^{*}$ One missing and $\dagger$ six missing.

TS, takotsubo syndrome.

For this sample, there was no clear pattern regarding costs according to socioeconomic factors, previous disease or risk factors; although there is a higher (statistically non-significant) mean cost in particular age groups and among men (table 3). As only five men participated in the study, further division based on sex was deemed unreliable.

The mean direct healthcare costs during the 6-month study period was $€ 10360$ (95\% CI: $€ 8310$ to $€ 12409$ ) among the 58 patients with TS. Of this, costs of $€ 8026$ $(77.5 \%)$ occurred during healthcare encounters for which at least one of the registered conditions was in the ICD chapter IX (I00-I99 circulatory system diseases). Costs of $€ 7135$ ( $68.9 \%$ of all costs) were for healthcare encounters in which the main condition was in ICD chapter IX.

During the study period, TS was found in ICD I42I429, which was also the category with the highest costs of all ICD categories analysed based on the main diagnosis of healthcare encounters (table 4). Other ICD categories with high costs, when analysing costs by main diagnosis, were I209, I200, I21-I219 and I5-I599. In addition to circulatory system diseases, the highest costs among TS patients were in the ICD categories mental and behavioural disorders and respiratory system disorders, and in the category, factors influencing health status and contacts with health services.

\section{DISCUSSION}

These findings indicate that the initial hospitalisation represents only two-fifths of the direct healthcare costs during the 6 months following diagnosis with TS. Additional costs were incurred by re-admissions, often for circulatory system disorders (including TS), and an average of more than 15 additional healthcare visits per patient during the period. Overall, circulatory system disorders were the main condition in healthcare encounters corresponding to almost $70 \%$ of all costs in this patient population.

We found little difference in cost of care related to age, country of birth and present or previous smoking behaviour. Patients with previous diagnoses of AMI, angina, stroke or hypertension had lower costs of care 


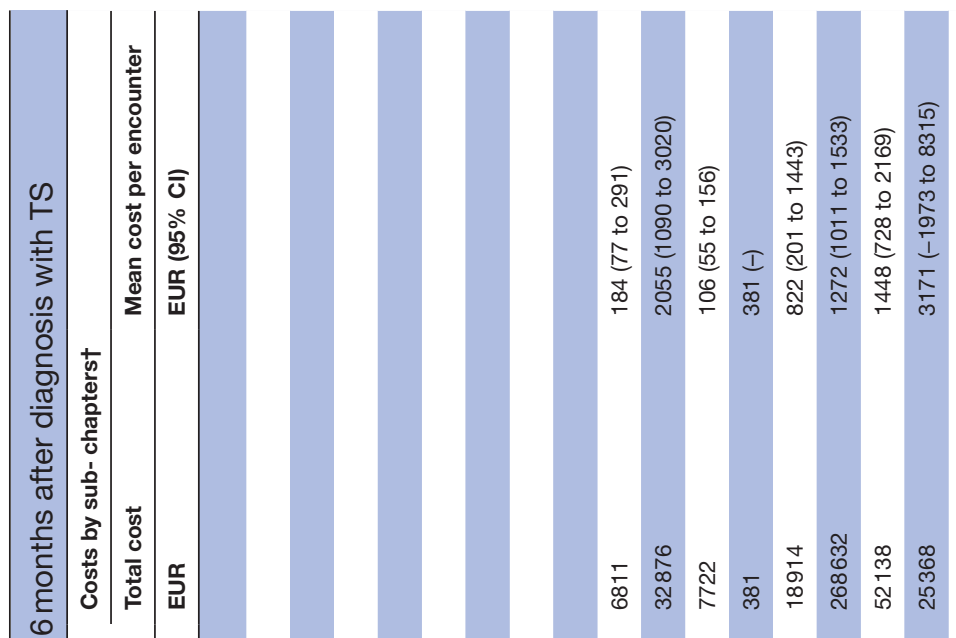

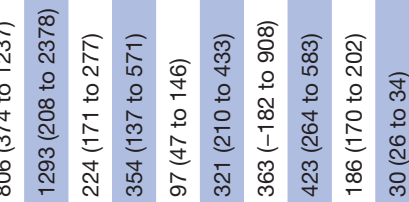

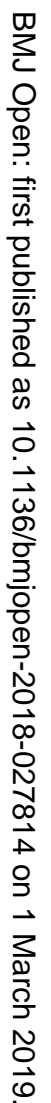

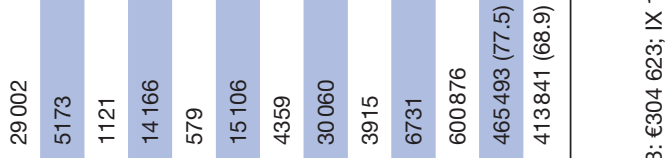

¿ั

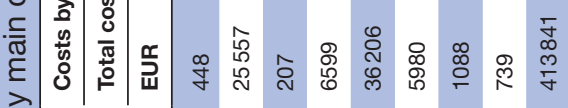

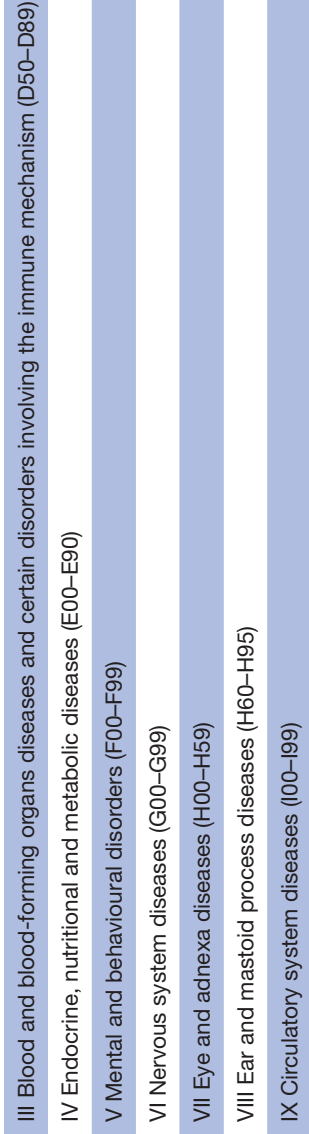

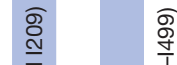

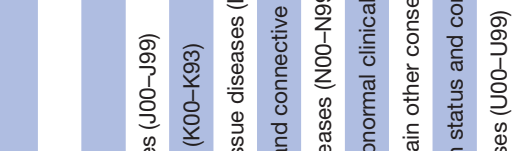
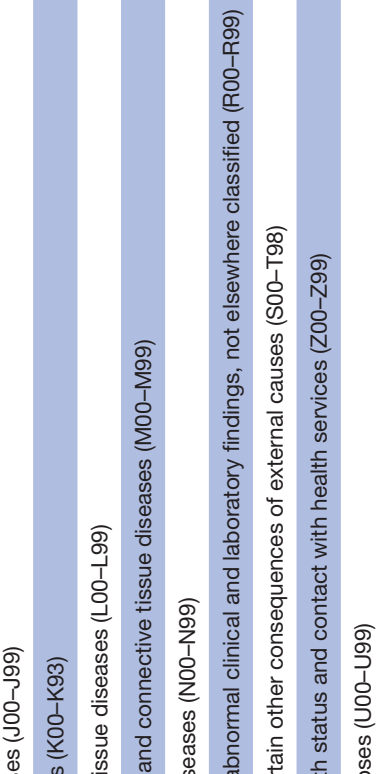

$\frac{d}{\frac{\partial}{d}}$

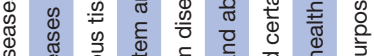

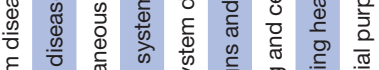

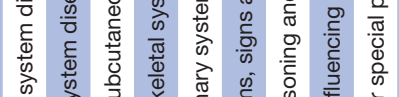


than those without but the differences were small and these results may not be generalizable to the population. Men had higher costs of care than women, but as only five men participated, this result should be viewed with caution and may not be reflected in a larger cohort. However, previous reports suggest that men suffer from more complications, ${ }^{9}$ and this may be reflected in the higher cost of care in our study. Despite the small number of men in the sample, the proportion and age are similar to that of larger cohorts. ${ }^{219}$ The proportion of patients with diabetes mellitus was lower than in previous studies, ${ }^{60}$ but similar to that of a larger Swedish cohort, ${ }^{4}$ and this may have affected the total cost of care.

The total average length of hospital stay during the study period was 10.2 days, the index hospitalisation constituted 6.4 days of this. Previous studies have reported average hospital stays of 3.6-8 days for the index hospitalisation. ${ }^{91021}$ Average length of stay in hospital decreased from 4.3 to 3.8 days between 2007 and 2012. ${ }^{21}$ In Sweden, the median hospital stay for patients $<80$ years old, who were discharged alive after an AMI, was 4 days in 2015. This had not changed since 2008. ${ }^{22}$ Common procedures during the hospitalisation were coronary angiography, Doppler echocardiogram, and conventional and oesophageal ECGs.

In the current study, we found that the total average healthcare cost per patient from hospitalisation to 6 months after discharge for TS was $€ 10360$, the equivalent of US $\$ 11491$, of which less than half the costs $(43.4 \%)$ were incurred during the index hospitalisation. This was not in line with the calculated average cost of US\$16 723 for only hospitalisation found by Khera et al. ${ }^{9}$ The large discrepancy in cost may be due to organisational differences between the health systems in Europe and the USA. The divergence between reported costs for TS hospitalisations in the previous two studies ${ }^{910}$ may be because of the difference between costs and charges in those two studies, as cost-to-charge ratios can vary between 0.12 and $0.96 .^{23}$

There were 40 re-admissions during the 6 months after initial discharge, 11 of which were during the first 30 days. This equals a 30 -day re-admission rate of $19 \%$, which is higher than the $11.6 \%$ that has previously been reported for patients with TS. ${ }^{21}$ No data on the 6-month or 1-year (all-cause) re-admission rate of patients with TS could be found, but the re-admission rate in Sweden 1 year after an AMI was $35 \%$ and $28 \%$ for females $65-75$ and $0-64$ years old, respectively. Approximately, half of these were for non-cardiovascular causes. ${ }^{22}$ The re-admission rate for patients with TS in this study is comparable $(34.5 \%)$ but in half the time. The proportion of non-cardiovascular causes for re-admission was also similar in the current study, 21 of 40 re-admissions had a non-cardiovascular main diagnosis. This indicates that health is affected after TS, which is in line with previous studies. ${ }^{24}{ }^{25}$ There is a large potential for cost savings if the re-admission rate can be reduced, even if this means increasing the number of outpatient and primary care visits. In the current study, the cost for the re-admissions ( $€ 169739$ ) was equivalent to the total cost of all outpatient and primary care encounters combined (€170 514).

In our study, most costs originated from ICD chapter IX (I00-I99 circulatory system diseases) and most of these costs related to sub-chapter I42-I49, which is where TS is usually diagnosed. There is no specific ICD-code for TS in the Swedish version of ICD-10 (in some countries, it is categories as I51.81, according to ICD-10-CM coding practices). This indicates that much of the care that these patients utilise relates to TS or other cardiovascular diseases. Other main conditions that rendered substantial costs originated from ICD chapters II (C00D48 neoplasms), V (F00-F99 mental and behavioural disorders) and X (J00-J99 respiratory system diseases). These costs are expected if one considers previously reported comorbidities for TS. Other TS comorbidities are neurological, renal and endocrine diseases, but there were small concurrent costs for these conditions in this sample. $^{620}$

Studies mapping resource use and costs related to a disease are commonly called COI studies. COI studies are often criticised for the lack of comparison between different healthcare programmes; thus, of less use in decision making. Although insufficient to provide guidance on treatment choices, descriptive COI estimates can be used to understand the magnitude of the disease in relation to other diagnoses, and identify patient groups for prioritising research and the development of intervention programmes. ${ }^{112627}$ In a disease like TS, where the preconception has been that the disease is relatively benign, ${ }^{48}$ and where follow-up guidelines are lacking, ${ }^{2} \mathrm{COI}$ can be a useful tool for putting the disease in perspective to other diagnoses. ${ }^{11}$ Furthermore, studies on the utilisation of healthcare resources after initial discharge from hospital are needed, as the health system and availability of, for example, specialised outpatient care will greatly affect the length of initial hospitalisation.

It appears from the results in this and previous studies that patients with TS have comparable re-admission rates as well as mortality rates as patients with AMI. ${ }^{4}$ Together, these results indicate that the healthcare of TS patients needs to be further developed, including a follow-up programme. Recent studies evaluating a person-centred intervention from hospital to primary care for patients with acute coronary syndrome found a significant increase in self-efficacy in the intervention group that was sustainable for up to 2 years. ${ }^{28} 29$ Follow-up programmes focusing the patient as a person with needs and abilities have proved efficient by, for example, reducing re-admissions to hospital in patients with severe chronic heart failure. ${ }^{30} 31$ Previous studies have also shown that patients with TS often have persisting symptoms, such as pain, fatigue and shortness of breath, for as long as 4 years after discharge 242532 and would, therefore, probably benefit from this kind of supportive follow-up programme. 


\section{Methodological discussion}

The main strengths of this study were the comprehensive data on resource use available in the VEGA database and medical records; thus, making follow-up feasible after the initial hospitalisation. The study was, however, limited by the small sample of patients, which was related both to the regional demarcation of the VEGA database (thus making inclusion of patients from other regions impossible) and set inclusion and exclusion criteria; only patients that had undergone coronary angiography were included (as the lack of a specific ICD-code for TS in the Swedish version of ICD-10, makes identification of TS more difficult), and patients with a predicted survival of less than 6 months were excluded from the study. Both factors may also influence utilisation of care, and its accompanying costs. Costs were calculated based on template costs, that is, the DRG weights and an average cost per DRG, and weighted costs from national statistics for primary care visits. These results are proxies for the actual healthcare costs, and calculations like these are used nationally to compare costs between, for example, counties. The estimated costs should, thus, include the burden to the healthcare system of standard treatments and examinations during healthcare encounters, but may to some extent fail to cover unusual healthcare interventions. Finally, the study was limited to 6 months after diagnosis; thus, increasing the follow-up compared with previous studies in this field but still neglecting costs occurring during later stages of the TS disease. This study period is, however, expected to cover most resource use related to TS, as the cardiac function usually recovers within that period. ${ }^{2}$ The study should be viewed as a first step towards a more comprehensive understanding of the economic burden of TS to the health system. Future studies are, thus, warranted of the long-term economic outcomes after TS. The introduction of a specific ICD-code for TS in the Swedish version of ICD is also needed and would make research easier and more reliable.

\section{CONCLUSION}

The current study shows that healthcare costs from hospitalisation to 6 months after discharge for TS primarily relate to a cardiac condition. Although there is frequent encounter with outpatient clinics and primary care, most costs stem from hospitalizations, of which re-admissions contributed substantially to the total cost. Patients with TS would probably benefit from a supportive follow-up programme after discharge from hospital.

Contributors SW and HG contributed to design and planning of the study, conducting and analyzing the data, and writing and reviewing the manuscript. $\mathrm{IE}, \mathrm{KU}$ and EO contributed to designing and planning the study, and writing and reviewing the manuscript.

Funding This work was supported by the Centre for Person-Centred Care (GPCC), University of Gothenburg, Sweden. GPCC is funded by the Swedish Government's grant for Strategic Research Areas, Care Sciences (Application to Swedish Research Council No. 2009-1088) and co-funded by the University of Gothenburg, Sweden. It was also supported in accordance to the Swedish agreement between the government and the county councils concerning economic support for providing an infrastructure for research and education of doctors (ALF). Swedish Heart and Lung Association (E093/13, E088/14 and E127/15), the Emelle Fund (161/14) and, Royal and Hvitfeldtska Foundation also contributed to the funding of the study.

Competing interests EO reports grants and personal fees from AstraZeneca, and grants from Abbott, outside the submitted work. SW, IE, KU and HG have no conflicts of interest to report.

Patient consent for publication Not required.

Ethics approval The study was approved by the Regional Ethical Review Board in Gothenburg (approval reference numbers: Dnr 275--11, T693-11, and T392-15) and complies with the Declaration of Helsinki.

Provenance and peer review Not commissioned; externally peer reviewed.

Data sharing statement All data relevant to the study are included in the article or uploaded as supplementary information.

Open access This is an open access article distributed in accordance with the Creative Commons Attribution Non Commercial (CC BY-NC 4.0) license, which permits others to distribute, remix, adapt, build upon this work non-commercially, and license their derivative works on different terms, provided the original work is properly cited, appropriate credit is given, any changes made indicated, and the use is non-commercial. See: http://creativecommons.org/licenses/by-nc/4.0/.

\section{REFERENCES}

1. Bybee KA, Kara T, Prasad A, et al. Systematic review: transient left ventricular apical ballooning: a syndrome that mimics ST-segment elevation myocardial infarction. Ann Intern Med 2004;141:858-65.

2. Lyon AR, Bossone E, Schneider B, et al. Current state of knowledge on Takotsubo syndrome: a position statement from the taskforce on Takotsubo Syndrome of the Heart Failure Association of the European Society of Cardiology. Eur J Heart Fail 2016;18:8-27.

3. Pilgrim TM, Wyss TR. Takotsubo cardiomyopathy or transient left ventricular apical ballooning syndrome: a systematic review. Int J Cardiol 2008;124:283-92.

4. Redfors B, Vedad R, Angerås $\mathrm{O}$, et al. Mortality in takotsubo syndrome is similar to mortality in myocardial infarction - A report from the SWEDEHEART registry. Int J Cardiol 2015;185:282-9.

5. Schultz T, Shao Y, Redfors B, et al. Stress-induced cardiomyopathy in Sweden: evidence for different ethnic predisposition and altered cardio-circulatory status. Cardiology 2012;122:180-6.

6. El-Sayed AM, Brinjikji W, Salka S. Demographic and co-morbid predictors of stress (takotsubo) cardiomyopathy. Am J Cardiol 2012;110:1368-72.

7. Omerovic E. Takotsubo syndrome: not as benign as once believed. Eur J Heart Fail 2016;18:657-9.

8. Stiermaier T, Moeller C, Oehler K, et al. Long-term excess mortality in takotsubo cardiomyopathy: predictors, causes and clinical consequences. Eur J Heart Fail 2016;18:650-6.

9. Khera R, Light-McGroary K, Zahr F, et al. Trends in hospitalization for takotsubo cardiomyopathy in the United States. Am Heart $J$ 2016;172:53-63.

10. Pant S, Deshmukh A, Mehta K, et al. Burden of arrhythmias in patients with Takotsubo cardiomyopathy (apical ballooning syndrome). Int J Cardiol 2013;170:64-8.

11. Tarricone R. Cost-of-illness analysis. What room in health economics? Health Policy 2006;77:51-63.

12. Osika Friberg I, Krantz G, Määttä S, et al. Sex differences in health care consumption in Sweden: a register-based cross-sectional study. Scand J Public Health 2016;44:264-73.

13. Bengtsson K, Jacobsson LT, Rydberg B, et al. Comparisons between comorbid conditions and health care consumption in rheumatoid arthritis patients with or without biological disease-modifying antirheumatic drugs: a register-based study. BMC Musculoskelet Disord 2016;17:499.

14. Wallerstedt SM, Bladh L, Ramsberg J. A cost-effectiveness analysis of an in-hospital clinical pharmacist service. BMJ Open 2012;2:e000329.

15. Sveriges kommuner och landsting (SKL). Prisindex. 2016 http://skl. se/ekonomijuridikstatistik/ekonomi/budgetochplanering/prisindex. 1331.html.

16. Sveriges kommuner och landsting (SKL). Statistik om hälso- och sjukvård samt regional utveckling 2014 Stockholm. 2015.

17. Sveriges Riksbank. Annual average exchange rate (aggregate). 2016 http://www.riksbank.se/en/Interest-and-exchange-rates/Annualaggregate-Exchange-rates/ (Accessed 21 Oct 2016). 
18. Thompson SG, Barber JA. How should cost data in pragmatic randomised trials be analysed? BMJ 2000;320:1197-200.

19. Templin C, Ghadri JR, Diekmann J, et al. Clinical features and outcomes of Takotsubo (Stress) cardiomyopathy. N Engl J Med 2015;373:929-38.

20. Pelliccia F, Parodi G, Greco C, et al. Comorbidities frequency in Takotsubo syndrome: an international collaborative systematic review including 1109 patients. Am J Med 2015;9:654.e11-9.

21. Murugiah K, Wang Y, Desai NR, et al. Trends in short- and long-term outcomes for takotsubo cardiomyopathy among medicare fee-forservice beneficiaries, 2007 to 2012. JACC Heart Fail 2016;4:197-205.

22. SWEDEHEART Annual report 2015. Uppsala: Uppsala Clinical Research Center (UCR), 2016.

23. Center RDA. Calculating cost: cost-to-charge ratios. $2013 \mathrm{http}: / /$ www.resdac.org/media/calculating-cost-cost-charge-ratios (Accessed 08 Dec 2016).

24. Wallström S, Ulin K, Omerovic E, et al. Self-reported symptoms 8 weeks after discharge: a comparison of takotsubo syndrome and myocardial infarction. Int J Cardiol 2016;224:348-52.

25. Wallström S, Ulin K, Omerovic E, et al. Symptoms in patients with takotsubo syndrome: a qualitative interview study. BMJ Open 2016;6:e011820.
26. Rice DP. Cost of illness studies: what is good about them? Inj Prev 2000;6:177-9.

27. Oxman AD, Fretheim A, Lavis JN, et al. SUPPORT Tools for evidence-informed health Policymaking (STP) 12: finding and using research evidence about resource use and costs. Health Res Policy Syst 2009;7(Suppl 1):S12.

28. Fors A, Ekman I, Taft C, et al. Person-centred care after acute coronary syndrome, from hospital to primary care - a randomised controlled trial. Int J Cardiol 2015;187:693-9.

29. Fors A, Swedberg K, Ulin K, et al. Effects of person-centred care after an event of acute coronary syndrome: two-year follow-up of a randomised controlled trial. Int J Cardiol 2017;249:42-7.

30. Hansson E, Ekman I, Swedberg K, et al. Person-centred care for patients with chronic heart failure - a cost-utility analysis. Eur $J$ Cardiovasc Nurs 2016;15:276-84.

31. Sahlen KG, Boman K, Brännström M. A cost-effectiveness study of person-centered integrated heart failure and palliative home care: Based on a randomized controlled trial. Palliat Med 2016;30:296-302.

32. Elesber AA, Prasad A, Lennon RJ, et al. Four-year recurrence rate and prognosis of the apical ballooning syndrome. J Am Coll Cardiol 2007;50:448-52. 